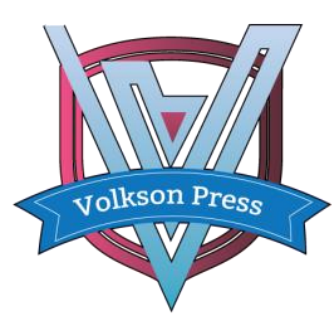

Contents List available at VOLKSON PRESS

Multidisciplinary Inclusive Education, Management

and Legal Services (MIEMLS)

Journal Homepage: https://topicsonsocialdevelop.com

DOI: $10.26480 /$ ismiemls.01.2018.68.70

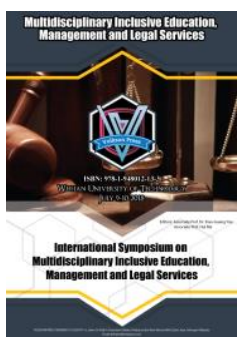

ISBN : 978-1-948012-13-3

\title{
IMPORTANT THEORIES OF SINGING AND VOCALIZATION
}

\author{
Xiang Hongxing* \\ Shanghai Normal University Tianhua College, North Shengxin Rd. Jiading, Shanghai, China \\ *Corresponding Author Email: hongxing33@126.com
}

This is an open access article distributed under the Creative Commons Attribution License, which permits unrestricted use, distribution, and reproduction in any medium, provided the original work is properly cited.

\section{ARTICLE DETAILS}

\section{Article History:}

Received 26 June 2018

Accepted 2 July 2018

Available online 1 August 2018

\section{ABSTRACT}

The basis and key to learning vocal singing is to scientifically recognize and use vocals, rather than to judge the quality of singing relying on personal experience. From history, we found many professional singers also have been lost. Yet there are also singers, vocal educators, voice research experts, physicists and other scientists who escort the singing learners. This paper reviews some important vocal theories in the history of vocal music development, such as vocal cord structure, Covered Tone, Mask Singing, Bernoulli effect and singing formant to facilitate vocal learners' reflection and exploration.

KEYWORDS

Vocal cord structure, Covered Tone, Mask Singing, Bernoulli effect, singing formant.

\section{INTRODUCTION}

Vocal singing cannot merely follow feelings. If singers do not know vocal theories and techniques, they will eventually be confused about vocal concepts and mechanism, and suffer from various diseases in the voice, which affects the singing life. Vocal training is based on physical principles. It is produced by collision of two forces rather than being extruded or pushed out. Vocal learners need to have a certain understanding of the vocal instrument, knowing the physical phenomena and principles in the formation of the voice, and be clear about the scientific scale and standard on judging whether a singer's tone is excellent or not. In a nutshell, day-today singing practice has to be in line with science, otherwise one acts in a way that defeats one's purpose and detracts from the life of singing.

\section{IMPORTANT THEORIES OF SINGING AND VOCALIZATION}

Vocal structure is a wind instrument, with three major components: the exciter, the resonator, and the radiator. To be more specific, the exciter is the vocal cord, the resonator is the vocal tract, and the radiator is the mouth and nose [1]. The exciter is a vocal cord, which can be thought of at the bottom of the throat. The vocal cord is a complex structure. Japanese vocal scientist found the multi-layer structure of the vocal cords-- the "body-cover theory" as Figure 1 [2].

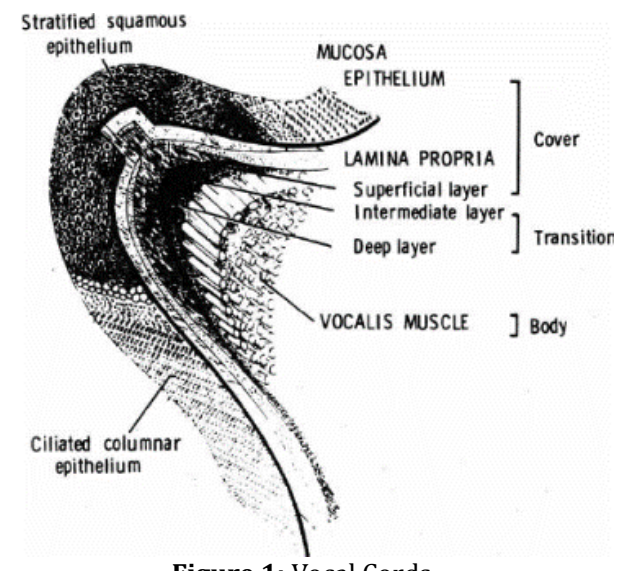

Figure 1: Vocal Cords
The vocal cords, from the outermost to innermost, are the cover layer, the transition layer and the body layer. The cover layer is the softest, flexible and adhesive, without shrinkage function. and the vocal cords are in contact with both edges and can vibrate like a fluid. The transition layer connects the cover layer and the body layer and plays a coordinating role. The body layer is hard and bears most of the weight of the vocal cords, providing stable support for the vocal cords.

The resonator is the vocal tract, the oropharynx tube when singing. Its length ranges from vocal cord to lips, and the average length is $17 \mathrm{~cm}$, as is shown in Figure $2[1,3]$.

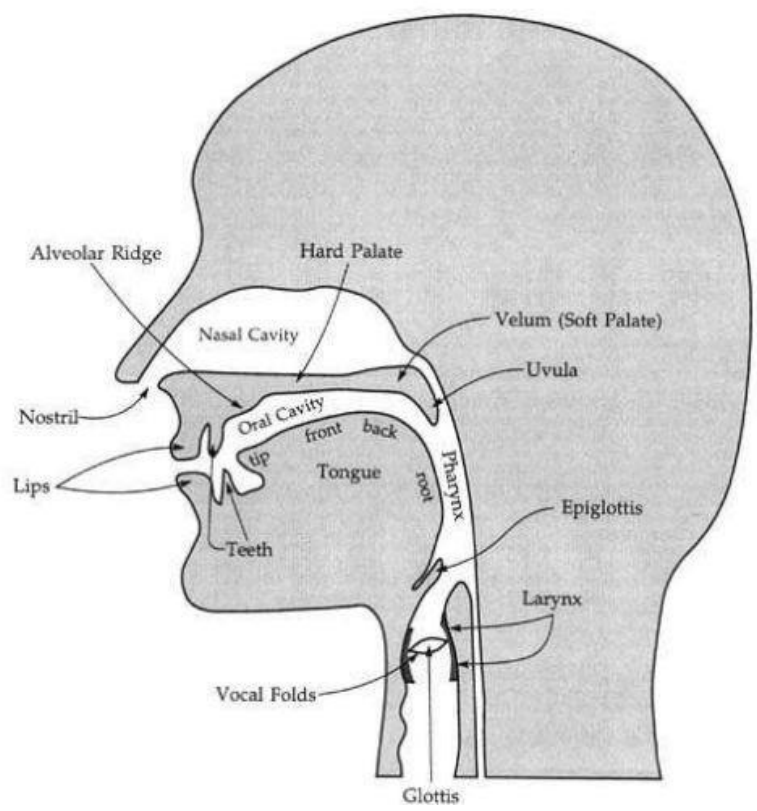

Figure 2: Vocal Tract

It is necessary to emphasize that in the vocal tract larynx is also a resonator. The laryngeal cavity, pharyngeal cavity and oral cavity in the vocal tract are a tube (channel), but when the aperture of larynx is 
narrowed down, the larynx and its upper channel break off and become separate cavities, forming the singing formant [4]. The radiator is the mouth and nose. The sound we feel is the vibration of the air in the channel (from the vibration of the vocal cords) radiated through the lips and nose and is transmitted to the ear through the outside air in the form of sound waves [1].

In the history of vocal music, singers have been biased in the issue of acquainting singing instruments, which has affected their singing career. French tenor Duprez (1806-1896), due to his own small volume, believed to find a singing method that enables to increase his volume--"Covered Tone (aka: Closed Tone)". The core method is: first, to lower the throat; second, to erect the epiglottis. He illustrated this method in his published The Art of Singing in 1846.

In 1837 he succeeded in the opera performance of Rossini's William Tell with his unprecedented loud voice and was praised by the great composer Berlioz. However, his glory didn't last long. Though he became famous at the age of 30, but he was unable to sing at the age of 43 and was forced to withdraw from the opera stage [3]. Dupree once wrote a letter to Rubini (1794 - 1854), who was a great singer with techniques, to inquire how to have a good singing quality. In the letter, Dupree asked why he himself lost voice at young age while Rubini still maintained his voice unharmed even after years of singing. In the reply, Rubini replied that Dupree always sang with the gifted principal voice, while he himself only used the interest of voice [5]. The Covered Tone is achieved by lowering the larynx and erecting the epiglottis to achieve the so-called grand volume. This is a kind of timbre camouflage, which sounds loud to the singer himself, but the sound is not beautiful, and can't be transmitted.

Jean de Reszk, the initiator of the Mask Singing, thought subjectively that the good voice of the singer was in the mask area, the place where a man wore a mask in western dance party. The only criterion for checking good singing is that there are vibrations at the bridge of the nose and the forehead. However, the mask singing theory was completely negated in the 20th century, because when the uvula is raised, the nasal cavity is blocked during the singing process. The thickness of the pharyngeal tube is like a pencil lead, and there is no vibration at the mask area. Reszk changed to baritone when he was 43 and bid farewell to the stage at the age of 50 .

Since the 1920s, scientists have begun to study the characteristics of the expert singer's voice, investigating the reason why professional singers' voice is bright, penetrating, and coherent. In 1927, Sergey Nikolayevitch Rzhevkin and Vladimir Sergeyevitch Kazansky, professors of physics at the Moscow State University in Soviet Union, discovered for the first time in the voices of trained professional singers (especially male voices) that there was an overtone peak around $500 \mathrm{~Hz}$, that is, the "low singing formant". The low formant in the voice makes the sound powerful, round and full. High singing formant was first discovered by the famous American acoustician found among good singers' voices, there was a high formant usually of $2400 \mathrm{~Hz}-3200 \mathrm{~Hz}$ [6]. This overtone peak makes the sound concentrated and metallic. Sundberg believes that the appearance of the singing formant is just where the band's sound energy is weakening, so when the singer's voice has a high formant, the vocal voice can surpass the band's cover, as shown in Figure 3 [4].

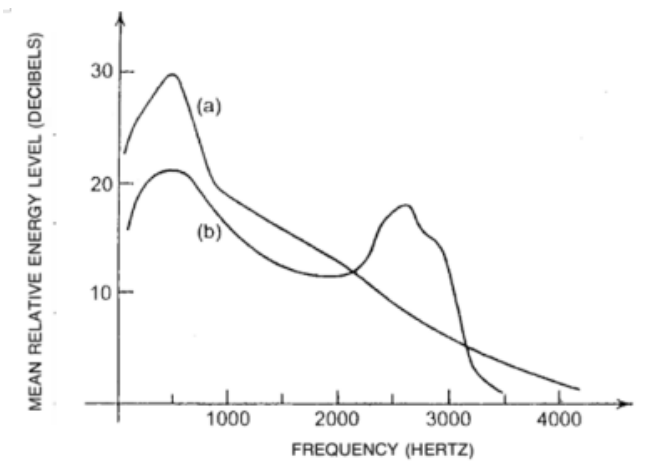

Figure 3: Singing Formant in a Tenor's Voice and Its Comparison with Symphony Orchestra
Figure 3 Curve b shows that in a tenor (Jussi Björling)'s voice, there is a singing formant of 2500 to $3000 \mathrm{~Hz}$. His singing is above the symphony orchestra's sound (curve a) and can compete with the symphony orchestra [3]. So the standard to judge whether the vocalist's tone is excellent or not is to observe whether the voice has low and high singing formants in their singing.

A good attack is crucial in the process of the formation of human singing voices. The attack is scientific and follow physiological rules, and the vocal cords' closure and vibration can be natural and free. In 1960, Vanden Berger proposed that the vocal cord closure is closely related to Bernoulli effect in fluid mechanics. The Bernoulli effect refers to the fact that as a fluid (air, liquid, etc.) flows through a horizontal tube with varying crosssectional areas, when flow rate increases in the narrow place, the pressure experienced by the fluid will be the lowest at a minimum cross-sectional area [3]. Similarly, if we straighten out the vocal tract, as the Figure 4 shows below,

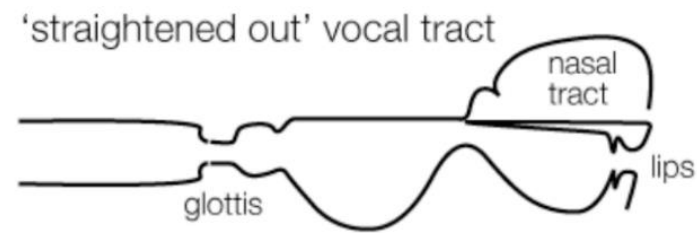

Figure 4: Straightened Out Vocal Tract

When one sings, the airflow from the trachea of the lung passes through the glottis (the area between the vocal cords), which is the narrowest part of the cross section of the vocal tract, the velocity of the breath is increased and the pressure is reduced, and the two vocal cords will naturally adsorb and gather together to vibrate. At this time, the vibration of the vocal cords is in the most desirable state during singing [7].

There are low and high formants in the human voice (low at 500-800 Hz and high at $2400-3200 \mathrm{~Hz}$ ). The formation of low formant is associated with the expansion of laryngeal and pharyngeal cavity. As for the condition to generate high formant, a study confirmed that the source of the high formant in the voice is the larynx itself [6]. High formant is a necessary condition for obtaining the most precious sound quality in Bel Canto to make the tone sound like a ring [7-10]. As for how to get the singing formant in the voice, Sundberg confirmed that the singer has three physiological requirements [4]:

(1) the bottom of the throat should be expanded;

(2) the laryngeal cavity should be lowered, and the channel should be about $17 \mathrm{~cm}$ long. The natural frequency is $500 \mathrm{~Hz}$;

(3) aperture of larynx should narrow down to less than a sixth of the cross-sectional area of the pharyngeal cavity bottom when the larynx and the pharynx become two separate cavities.

At this time, the larynx is a resonance cavity that forms a singing formant, which can generate a high formant at $2800-2900 \mathrm{~Hz}$.

\section{CONCLUSION}

In summary, vocal music learning should be based on science, and it will do more with less. Otherwise, with thousands of practices, one only acts in a way that defeats one's purpose, unable to obtain good sound quality, and even harmful to singing instruments. Vocal music learning is

\section{REFERENCE}

[1] Ziwei, B. 1981. The Acoustic Problem of Singing and Music for the National High School Music School Students' Vocal Competition Conference. Music Art: Journal of Shanghai Conservatory of Music, (1), 52 59

[2] Hirano, M. 1975. Function of the laryngeal muscles in singing. The Journal of the Acoustical Society of America, 58 (S1), S95-S95.

[3] Ruilin, N. 2007. Bel Canto, its development trajectory and some important interpretations of its vocalization mechanism. Musical Art: Journal of Shanghai Conservatory of Music, (1), 71-93.

[4] Sundberg, J. 1977. The acoustics of the singing voice. Scientific American, 236 (3), 82-91.

[5] Herbert-Caesari, E.F. 1951. The voice of the mind. R. Hale. 
[6] Bartholomew, W.T. 1934. A Physical Definition of "Good Voice-Quality in the Male Voice. the Journal of the Acoustical Society of America, 6 (1), 25-33.

[7] Vernnard, W. 1967. Singing, the Mechanism and Technique. Carl Fischer.

[8] Anonymous. 2018. (n.d.). Retrieved August 1, from: https://musicaltheatreresources.files.wordpress.com/2016/02/phoneti csvocaltract.jpg? $\mathrm{w}=284 \& \mathrm{~h}=300$

[9] Department of Vocal Music. 1980. Shanghai Conservatory of Music. Vocal Translation Series, First Series.

[10] Hirano, M. 1982. The role of the layer structure of the vocal fold in register control. Vox Humana. University of Jyvaskyla, 50Á. 